\title{
Reflections
}

\section{Martha's forest}

$M$ artha spends more and more of her time in the woods these days. After all, she planted every tree herself. She runs her fingers over the rough bark of that ancient oak where Lord Samuel and Lady Veronica swore their oath of eternal love. Martha likes the way the breeze strokes her face as she makes her way through the dappled light to the banks of the brook w where, amongst those lindens, Samantha first met the Dark Young Stranger whose child she later bore (to her family's undying shame). On the far side of the brook, you'll find the fragrant patch of juniper where Martha can still hear the sticky crimson gush against the green when Elizabeth, deserted by Sir Charles, used his dagger to take her own life.

Many of the residents cry out from their beds in rage or horror as the amyloid plaques and neurofibrillary tangles gnaw at their withered minds. Martha,

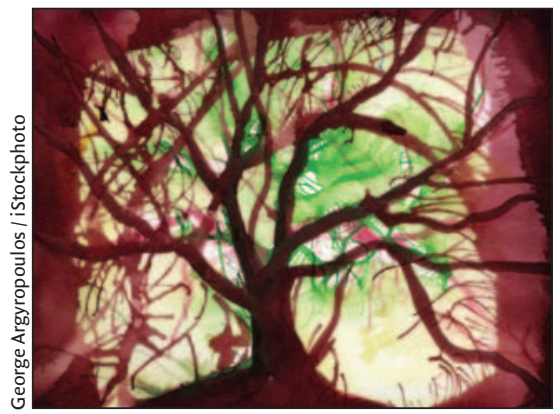

though, is quiet. Most of the nurses wonder why. But a few of them have browsed the Romance section of that used book store next to the shopping centre and picked up yellowed copies of I or 2 of the 73 novels by Martha T. Drummond. They've carefully turned pages brittle as October leaves. And they understand why Martha's quiet, why a soft smile so often plays about her mouth or why a tear hangs against her eye lid. They know where Martha is.

\section{Andrew Kirk MD}

Department of Neurology

University of Saskatchewan

Saskatoon, Sask.

\section{Poetry}

\section{Love squawks through technology}

Dr. X sits in his home study, listening to Ella Fitzgerald, tying flies, considering cancelling the New England Journal. Occasionally the intercom buzzes:

Mr. McGuire has lost a thumb in the thresher, little Beatrice is inconsolable with a sore ear, Madame Plante has the gout again.

Dr. X triages,

judges best how to spend his time:

two aspirin advice, or l'll come down and see you.

The intercom is sublime; no need to answer the door, just push a button.

The sound is squawky, and some patients swear that Dr. X told them to gargle elephants or to juggle toilet bowls or, more mysteriously,
Dr. X heard some strange things too: that a woman had catbox on her face, that a child was seething with child, that a divorcee with compression needed to till the field. No wonder what he said back seemed interplanetary take the train, take the train.

But one evening a woman buzzed him, Brrrringorrahmarahm, and said how much she brought her husband, how they sang ditties and splayed, how taking the train had solved their conjugal flight risk, how dinners now are spent at Erin Village Riviera and rooftop shouts are whoops,

whoop-te-do's, and the tax man cometh for joy.

Dr. X, being an experienced physician, had no idea who the woman was, but he knew what to do, and said you're welcome, keep taking the train.

\section{Shane Neilson MD \\ Family physician \\ Guelph, Ont.}

